\title{
Synthesis and Characterization of $\mathrm{Gd}_{2} \mathrm{O}_{2} \mathrm{~S}: \mathrm{Pr}^{3+}$ Nanophosphors using Gamma Irradiation Method \\ (Sintesis dan Pencirian Nanofosfor $\mathrm{Gd}_{2} \mathrm{O}_{2} \mathrm{~S}: \mathrm{Pr}^{3+}$ menggunakan Kaedah Gama Iradiasi)
}

\author{
MUHAMMAD HASSYAKIRIN HASIM, IRMAN ABDUL RAHMAN*, SAPIZAH RAHIM, \\ MUHAMMAD TAQIYUDDIN MAWARDI AYOB, LIYANA MOHD ALI NAPIA \\ \& SHAHIDAN RADIMAN
}

\begin{abstract}
Praseodymium ion, $\mathrm{Pr}^{3+}$ doped $\mathrm{Gd}_{2} \mathrm{O}_{2} \mathrm{~S}$ nanophosphors were successfully synthesized via gamma irradiation route along with the heat treatment. The effect of the gamma irradiation (0-150 kGy) on the structural, morphology and photoluminescence properties of $\mathrm{Gd}_{2} \mathrm{O}_{2} \mathrm{~S}: \mathrm{Pr}^{3+}$ were characterized via X-ray diffraction (XRD), field emission scanning electron microscope (FESEM) and photoluminescence spectroscopy (PL). The thermal properties of precursor sample were tested by the thermogravimetric analysis (TGA) and differential thermal analysis (DTA). The chemical bonding of the precursor samples were analyzed by Fourier transform infrared spectroscopy (FT-IR). The XRD result confirmed the formation of hexagonal phase of $\mathrm{Gd}_{2} \mathrm{O}_{2} \mathrm{~S}: \mathrm{Pr}^{3+}$ without the presence of any impurities. The FESEM inspection showed the non-symmetrical shape of particles transformed into grain-like shape. The optimum photoluminescence (PL) emission intensities of $\mathrm{Gd}_{2-x} \mathrm{O}_{2} \mathrm{~S}: x \mathrm{Pr}^{3+}$ occur at $50 \mathrm{kGy}$ dose of gamma irradiation and $2 \mathrm{~mol} \%$ concentration dopant of $\mathrm{Pr}^{3+}$ ions. The spectra under $325 \mathrm{~nm}$ UV excitation shows a strong green emission at $515 \mathrm{~nm}$, which match the ${ }^{3} \mathrm{P}_{0} \rightarrow{ }^{3} \mathrm{H}_{4}$ transition of $\mathrm{Pr}^{3+}$ ions. The $\mathrm{Gd}_{2} \mathrm{O}_{2} \mathrm{~S}: \mathrm{Pr}^{3+}$ nanophosphors possessed many useful approaches in various applications mainly as radiation detection and biomedical diagnostic.
\end{abstract}

Keywords: Gadolinium oxysulfide; gamma irradiation; praseodymium doped

\section{ABSTRAK}

Nanofosfor $\mathrm{Gd}_{2} \mathrm{O}_{2} \mathrm{~S}$ didop ion praseodimium, $\mathrm{Pr}^{3+}$ berjaya disintesis melalui kaedah penyinaran gama bersama dengan rawatan haba. Kesan penyinaran gama (0-150 kGy) terhadap sifat struktur, morfologi dan kefotopendarcahayaan $\mathrm{Gd}_{2} \mathrm{O}_{2} \mathrm{~S}: \mathrm{Pr}^{3+}$ dicirikan melalui alat pembelauan sinar-X (XRD), mikroskop imbasan pancaran medan elektron (FESEM) dan spektroskopi kefotopendarcahayaan (PL). Sifat terma sampel pelopor diuji oleh analisis termogravimetrik (TGA) dan analisis pembezaan terma (DTA). Ikatan kimia sampel pelopor dianalisis oleh spektroskopi inframerah transformasi Fourier (FT-IR). Keputusan XRD mengesahkan pembentukan fasa heksagon $\mathrm{Gd}_{2} \mathrm{O}_{2} \mathrm{~S}: \mathrm{Pr}^{3+}$ tanpa kehadiran sebarang bendasing. Pemeriksaan FESEM mendedahkan bentuk zarah tak simetri berubah menjadi bentuk seakan bijian. Keamatan pemancaran kefotopendarcahayaan (PL) yang optimum $\mathrm{Gd}_{2-x} \mathrm{O}_{2} \mathrm{~S}: \mathrm{xPr}^{3+}$ adalah pada dos terserap $50 \mathrm{kGy}$ dan $2 \mathrm{~mol} \%$ kepekatan dop ion $\mathrm{Pr}^{3+}$. Spektrum bawah pengujaan UV $325 \mathrm{~nm}$ menunjukkan pancaran hijau yang kuat pada $515 \mathrm{~nm}$ sepadan dengan peralihan ${ }^{3} \mathrm{P}_{0} \rightarrow{ }^{3} \mathrm{H}_{4}$ oleh ion $\mathrm{Pr}^{3+}$. Nanofosfor $\mathrm{Gd}_{2} \mathrm{O}_{2} \mathrm{~S}: \mathrm{Pr}^{3+}$ memiliki banyak pendekatan yang berguna dalam pelbagai aplikasi terutamanya sebagai pengesanan sinaran dan diagnostik bioperubatan .

Kata kunci: Dop praseodimium; Gadolinium oksisulfid; penyinaran gama

\section{INTRODUCTION}

Nanophosphors have attracted lots of attention among the researchers due to its variety of potential applications especially in high performance resolution of displays and devices. The extensively used display and device applications had always been ceramic scintillator (Greskovich \& Duclos 1997), cathode ray tubes (CRTs) (Som et al. 2013), multimodal imaging agent (Osseni et al. 2014) and charge-coupled devices (CCD) (Faruqi \& Tyrell 1999). A series of nanophosphors materials have been developed in the last few years such as $\mathrm{BaY}_{2} \mathrm{ZnO}_{5}: \mathrm{Dy}^{3+}$ (Sonika et al. 2015), $\mathrm{Y}_{8} \mathrm{~V}_{2} \mathrm{O}_{17}: \mathrm{Eu}: \mathrm{Yb}$ (Dwivedi \& Zilio 2013), $\mathrm{Lu}_{2} \mathrm{O}_{3}: \mathrm{Eu}$ (Seferis et al. 2014) and ZnS (Manam et al. 2010). However, among the series of nanophosphors materials mentioned above, $\operatorname{Pr}^{3+}$ ion doped gadolinium oxysulfide $\left(\mathrm{Gd}_{2} \mathrm{O}_{2} \mathrm{~S}: \mathrm{Pr}^{3+}\right)$ is the foremost candidate due to its high physical/chemical stability and high thermal stability (Wang et al. 2013). $\mathrm{Gd}_{2} \mathrm{O}_{2} \mathrm{~S}: \mathrm{Pr}^{3+}$ also possessed wide energy band gap (4.6-4.8 $\mathrm{eV})$ that is suitable for doping of trivalent rare earth ions, high density (7.34 $\mathrm{g} \mathrm{cm}^{-3}$ ) and high atomic number of $\mathrm{Gd}$ (64) which gives high stopping power of $\mathrm{X}$-ray radiation (Lian et al. 2010). It featured favourable intrinsic X-ray to convert the light efficiently which is 1.8 times greater light output than $\mathrm{CaWO}_{4}$ (Lian et al. 2011). All of these unique characteristics allow to more efficient fabrication 
of radiation detector, produce high quality display, and lower noise exposure of X-ray imaging system.

Lots of number of synthesis routes have existed nowadays, for instance; co-precipitation method (Wang et al. 2010), solvothermal method (Huang et al. 2012), microwave solid state method (He et al. 2015), high temperature combustion method (He et al.2015), vacuum firing method (Wang et al. 2013) and microemulsion liquid method (Liu et al. 2008). But, the main problems of all these methods were the difficulty to control the size of particles and produced the phosphor in nanoscale. To the best of our knowledge, no researchers have ever been utilized the gamma irradiation method to synthesize $\mathrm{Gd}_{2} \mathrm{O}_{2} \mathrm{~S}: \mathrm{Pr}^{3+}$. In this work, we chose this method due to its simplicity in terms of providing pure and highly stable state of metals (Naghavi et al. 2010); chemical safe and friendly environmental. Besides, the heat treatment process in the last procedure does not employed any toxic or poisonous chemicals. Furthermore, the gamma irradiation method can also produce well dispersed and small size particles. The production occurs due to the radiolysis process in any aqueous solution which created hydrated electron $\left(\mathrm{e}_{\mathrm{aq}}{ }^{-}\right)$ and radical species (Jurkin et al. 2016; Sharin et al. 2015). The hydrated electron $\left(\mathrm{e}_{\mathrm{aq}}{ }^{-}\right)$reduce the $\mathrm{Gd}^{3+}$ to become $\mathrm{Gd}^{0}$, which can also reduce the particles size and modify the particles shape. In this work, the effect of gamma irradiation doses towards the structural, morphology and photoluminescence properties of $\mathrm{Gd}_{2} \mathrm{O}_{2} \mathrm{~S}: \mathrm{Pr}^{3+}$ will be discussed in details. The formation mechanism will also be discussed based on the thermal and chemical analysis.

\section{MATERIALS AND METHODS}

\section{PREPARATION OF GD $\mathrm{O}_{2} \mathrm{~S}: \mathrm{PR}^{3+}$ NANOPHOSPHORS}

The starting materials were gadolinium (III) nitrate hexahydrate, $\mathrm{Gd}\left(\mathrm{NO}_{3}\right)_{3} \bullet 6 \mathrm{H}_{2} \mathrm{O}(99.9 \%)$, praseodymium (III) nitrate hexahydrate, $\operatorname{Pr}\left(\mathrm{NO}_{3}\right)_{3} \cdot 6 \mathrm{H}_{2} \mathrm{O}(99.9 \%)$ and cetyltrimethylammonium bromide, СТAB (98\%) which were purchased from Sigma-Aldrich. Ammonium sulfate $\left(\left(\mathrm{NH}_{4}\right)_{2} \mathrm{SO}_{4}\right)$ purchased from Merck was used as the sulfurizing agent. All chemicals were used without any further purification.

In our previous work (Hasim et al. 2017), a typical procedure ran as follows: The $\mathrm{Gd}\left(\mathrm{NO}_{3}\right)_{3} \cdot 6 \mathrm{H}_{2} \mathrm{O}(0.02 \mathrm{M})$ and different concentration of $\operatorname{Pr}\left(\mathrm{NO}_{3}\right)_{3} \bullet 6 \mathrm{H}_{2} \mathrm{O}(1,2,5$ and $10 \mathrm{~mol} \%$ ) were dissolved in deionized water and stirred in an hour. Later, the dissolved $\left(\mathrm{NH}_{4}\right)_{2} \mathrm{SO}_{4}(0.03 \mathrm{M})$ was dropwised into the mixed nitrate solution $\left(\mathrm{Gd}\left(\mathrm{NO}_{3}\right)_{3}\right.$ and $\left.\operatorname{Pr}\left(\mathrm{NO}_{3}\right)_{3}\right)$. Afterwards, the solution of CTAB (0.02 $\mathrm{M})$ dissolved and added into the mixture solution. The mixtures were stirred overnight and then separated into 4 bottles. $1 \mathrm{~mL}$ of isopropanol was dropped into each of the bottles before irradiated by gamma source, Cobalt-60 in the GammaCell 220 Excel irradiator at a dose rate of 1.45 $\mathrm{kGy} / \mathrm{h}$. The isopropanol was used in order to restrict the oxidation due to the undesired oxidizing species such as hydroxyl radical. The exposed gamma doses used were
50, 100 and $150 \mathrm{kGy}$, while $0 \mathrm{kGy}$ was used as a control sample. Once the irradiation process was completed, the white solid precipitates were retrieved via centrifugation (4000 rpm) and washed with ethanol several times. The washed precipitates were dried in an oven at $80^{\circ} \mathrm{C}$ for $24 \mathrm{~h}$ and then undergo a heat treatment with the temperature at $900^{\circ} \mathrm{C}$ for $2 \mathrm{~h}$ along with the flow of hydrogen gas. Finally, the products were cooled down to room temperature and the $\mathrm{Gd}_{2-x} \mathrm{O}_{2} \mathrm{~S}: x \mathrm{Pr}^{3+}(x=1,2,5$ and $10 \mathrm{~mol} \%)$ nanophosphors successfully obtained.

The thermogravimetric analysis (TGA) and differential thermal analysis (DTA) of precursor sample was analyzed by Mettler Toledo, TGA/SDTA 851e instrument. The phase and crystal structure of samples were studied by X-ray diffraction, XRD (Bruker, D8 Advance) with a wavelength of $\mathrm{Cu} \mathrm{K} \alpha(\lambda=0.15406 \mathrm{~nm})$. The field emission scanning electron microscopy, FESEM (Carl Zeiss, Supra 35VP) used to observe morphology and size particles of $\mathrm{Gd}_{2} \mathrm{O}_{2} \mathrm{~S}: \mathrm{Pr}^{3+}$. The photoluminescence (PL) emission spectra of $\mathrm{Gd}_{2}$ $\mathrm{O}_{2} \mathrm{~S}: x \mathrm{Pr}^{3+}(x=1,2,5$ and $10 \mathrm{~mol} \%)$ nanophosphors were measured via FLSP920 Edinburgh spectrometer.

\section{RESULTS AND DISCUSSION}

\section{FORMATION MECHANISMS}

OF GD $\mathrm{O}_{2} \mathrm{~S}: \mathrm{PR}^{3+} \mathrm{NANOPHOSPHORS}$

The thermal analysis was done using thermogravimetric analysis (TGA) and differential thermal analysis (DTA) in order to understand the decomposition behaviour of the precursor samples. Additionally, the TGA-DTA test also allowed us to understand the formation mechanisms of $\mathrm{Gd}_{2} \mathrm{O}_{2} \mathrm{~S}: \mathrm{Pr}^{3+}$. The TGA-DTA thermogram is shown in Figure 1. The test was conducted with the temperature range from room temperature, $25^{\circ} \mathrm{C}$ to $900^{\circ} \mathrm{C}$. It can be seen that the total weight loss mainly consists of three weight loss steps and the overall weight loss is $49.91 \%$. The first step weight loss was from room temperature to $280^{\circ} \mathrm{C}$ indicating the loss of physically water molecules, $\mathrm{H}_{2} \mathrm{O}$. The weight loss corresponded to the DTA curve which points out to the endothermic peak. The second step weight loss was between the temperatures from $280^{\circ} \mathrm{C}$ to $500^{\circ} \mathrm{C}$ which is related to the decomposition of carbon ion $\left(\mathrm{CO}_{3}{ }^{2-}\right)$ from CTAB surfactant. The decomposition matched well to the DTA curves which show the strong endothermic peak around $402^{\circ} \mathrm{C}$ to $537^{\circ} \mathrm{C}$, while the final step weight loss was considered as the oxygenation process due to the phase change of the precursor sample which corresponded to the following reaction:

$$
\mathrm{Gd}_{2}\left(\mathrm{SO}_{4}\right)_{3}: \mathrm{Pr}^{3+}+\mathrm{O}_{2} \rightarrow \mathrm{Gd}_{2} \mathrm{O}_{2} \mathrm{SO}_{4}: \operatorname{Pr}^{3+}
$$

The reaction will be furthered in order to obtain the final product of $\mathrm{Gd}_{2} \mathrm{O}_{2} \mathrm{~S}: \mathrm{Pr}^{3+}$. The sample of $\mathrm{Gd}_{2} \mathrm{O}_{2} \mathrm{SO}_{4}: \mathrm{Pr}^{3+}$ will once more undergo calcinations at $900^{\circ} \mathrm{C}$ in $2 \mathrm{~h}$, at this moment the flow of hydrogen gas was utilized by placing the $\mathrm{Gd}_{2} \mathrm{O}_{2} \mathrm{SO}_{4}: \mathrm{Pr}^{3+}$ sample into the tube furnace. The reaction can be described as follows: 


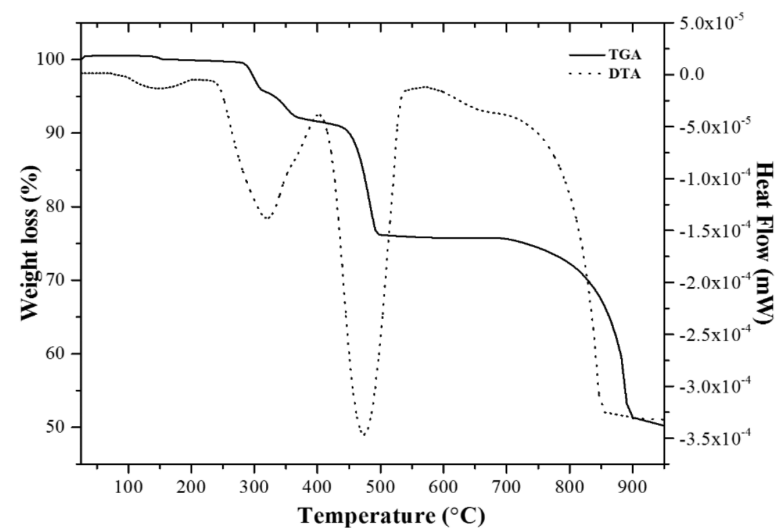

FIGURE 1. TGA-DTA thermogram of precursor sample

$$
\mathrm{Gd}_{2} \mathrm{O}_{2} \mathrm{SO}_{4}: \mathrm{Pr}^{3+}+4 \mathrm{H}_{2} \rightarrow \mathrm{Gd}_{2} \mathrm{O}_{2} \mathrm{~S}: \mathrm{Pr}^{3+}+4 \mathrm{H}_{2} \mathrm{O}
$$

The final reaction is called the deoxygenation reaction due to the removable of oxygen ion, $\mathrm{O}^{2-}$ from the $\mathrm{Gd}_{2} \mathrm{O}_{2} \mathrm{SO}_{4}: \mathrm{Pr}^{3+}$ by the hydrogen gas, $\mathrm{H}_{2}$.

The FT-IR spectra of each phase are shown in Figure 2. The spectra of the precursor sample $\left(\mathrm{Gd}_{2}\left(\mathrm{SO}_{4}\right)_{3}: \mathrm{Pr}^{3+}\right)$ gives a broad peak located at the $3220 \mathrm{~cm}^{-1}$. The peak was appeared due to the $\mathrm{O}-\mathrm{H}$ bonding stretch in the sample (Manigandan et al. 2015), which also indicated to the existence of hydroxyl water. While for the samples of $\mathrm{Gd}_{2} \mathrm{O}_{2} \mathrm{SO}_{4}: \mathrm{Pr}^{3+}$ and $\mathrm{Gd}_{2} \mathrm{O}_{2} \mathrm{~S}: \mathrm{Pr}^{3+}$, the $\mathrm{O}-\mathrm{H}$ bonding peak clearly disappeared and became a straight line. The removal of hydroxyl water from both samples can be confirmed as the precursor sample was calcined with the temperature reached $900^{\circ} \mathrm{C}$. The aromatic $\mathrm{C}=\mathrm{C}$ peaks originated from СТAB surfactant also observed in the wavenumber range from 1631 to $1426 \mathrm{~cm}^{-1}$ by the precursor sample. Furthermore, the entire spectra show sharp peaks located at 1061 and $615 \mathrm{~cm}^{-1}$ can be attributed to the $\mathrm{SO}_{4}{ }^{2-}$ anion group (Lian et al. 2011). The sharp peak located at 427 $\mathrm{cm}^{-1}$ for all the phase spectra can be linked to the bonding vibration of Gd-S and Gd-O (Lian et al. 2010).

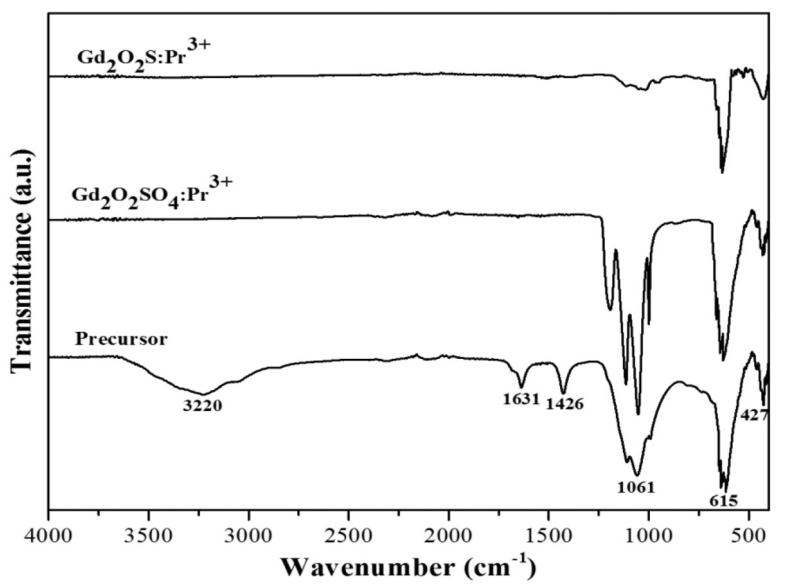

FIGURE 2. FT-IR spectra of the precursor, $\mathrm{Gd}_{2} \mathrm{O}_{2} \mathrm{SO}_{4}: \mathrm{Pr}^{3+}$, $\mathrm{Gd}_{2} \mathrm{O}_{2} \mathrm{~S}: \mathrm{Pr}^{3+}$ samples
EFFECT OF GAMMA IRRADIATION ON PROPERTIES OF $\mathrm{GD}_{2} \mathrm{O}_{2} \mathrm{~S}: \mathrm{PR}^{3+}$ NANOPHOSPHORS

The X-ray diffraction (XRD) patterns of the $\mathrm{Gd}_{1.90} \mathrm{O}_{2} \mathrm{~S}: 10 \% \mathrm{Pr}^{3+}$ nanophosphors were shown in Figure 3 along with the standard file of $\mathrm{Gd}_{2} \mathrm{O}_{2} \mathrm{~S}$ from Joint Committee on Powder Diffraction Standards (JCPDS) No: 00-26-1422. It can be seen that all the diffraction peaks corresponded well to the standard file. The calculated lattice constants were $\mathrm{a}=\mathrm{b}=3.853 \AA$, $\mathrm{c}=6.665 \AA$ similar to the reference data lattice constant $(\mathrm{a}=\mathrm{b}=3.852 \AA$, c $=6.665 \AA$ ), thus confirmed the diffraction peaks were indexed as a pure hexagonal phase and P-3m1(164) space group (Wei et al. 2015). The sharpness of XRD peaks also increased with the increasing of the gamma irradiation doses. The XRD analysis of the $150 \mathrm{kGy}$ sample exhibits strongest and sharpest diffraction peaks. It can be concluded that the crystallinity phase of $150 \mathrm{kGy}$ sample is the highest compared to the other samples. The absence of the unknown diffraction peaks also indicated that there were no any other impurities appeared and the $\operatorname{Pr}^{3+}$ ion doped well into the $\mathrm{Gd}_{2} \mathrm{O}_{2} \mathrm{~S}$ interstitial site.

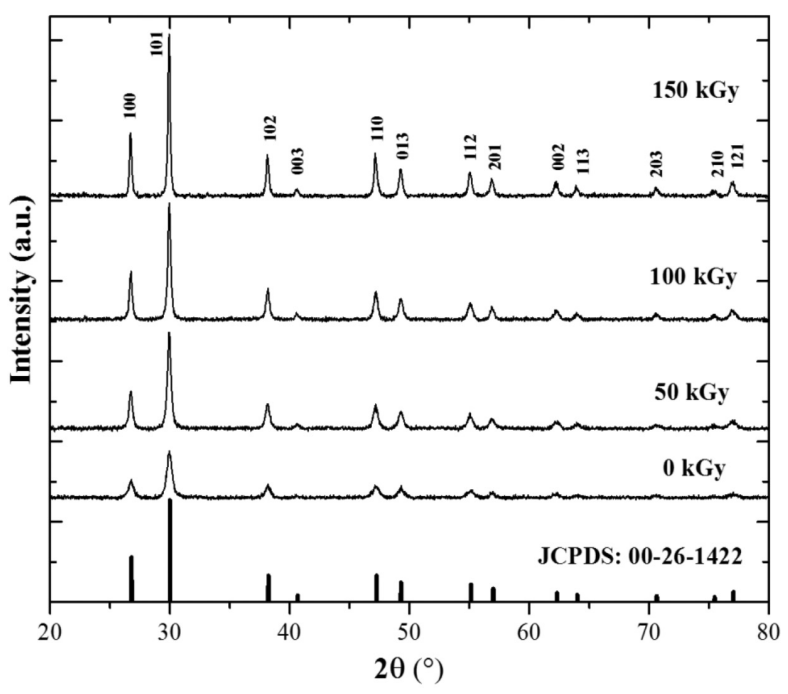

FIGURE 3. XRD patterns of $\mathrm{Gd}_{1.90} \mathrm{O}_{2} \mathrm{~S}: 10 \% \mathrm{Pr}^{3+}$ nanophosphors of each irradiation doses: $0 \mathrm{kGy}, 50 \mathrm{kGy}, 100 \mathrm{kGy}$ and $150 \mathrm{kGy}$

Furthermore, in order to calculate the average crystallite sizes of the particles, the Scherrer's equation was used:

$$
D_{h k l}=\frac{K \lambda}{\beta \cos \theta}
$$

where $D$ is the average crystallite sizes, $(h k l)$ defines as the size along the direction, $K$ considered as a constant (0.941) and $\lambda$ is the X-ray wavelength $(0.15405 \mathrm{~nm})$, while the $\theta$ and $\beta$ are diffraction angle and full-width at half maximum (FWHM), respectively. The three strongest peaks selected were $2 \theta=26.717^{\circ}(100), 29.850^{\circ}(101)$ and $38.085^{\circ}$ (102) used to calculate average crystallite sizes, 
D. The range average crystallite sizes obtained of all the samples were between 25 and $35 \mathrm{~nm}$.

The typical FESEM images in Figure 4 shows the surface morphology of $\mathrm{Gd}_{1.90} \mathrm{O}_{2} \mathrm{~S}: 10 \% \mathrm{Pr}^{3+}$ for the 0, 50, 100 and $150 \mathrm{kGy}$ samples. The $0 \mathrm{kGy}$ sample consists of non-symmetrical shape and agglomerated growth of particles. The sample also displayed bulky size of particles which more than $1 \mu \mathrm{m}$ of length. As the dose reached 50 $\mathrm{kGy}$, the bulky particles started to rip apart and dispersed. Afterwards, the particles of $100 \mathrm{kGy}$ and $150 \mathrm{kGy}$ developed to be well more dispersed and grain-like shape. The grain-like particles of both samples show identical measurement with a length $\times$ width of $\sim 30 \mathrm{~nm} \times 20 \mathrm{~nm}$.

The transformation of surface morphology from large to smaller size of particles was due to the radiolysis process when the samples (in liquid form) were irradiated. The released of hydrated electron $\left(\mathrm{e}_{\mathrm{aq}}^{-}\right)$and radical species (4) were affected the $\mathrm{CTAB}$ aqueous solution at the various locality which modified the surface morphology of sample and then transformed the shape of particles (Hasim et al. 2017). The size of particles became smaller due to the higher nucleation occurrence than the total ions at high irradiation doses, while at lower irradiation doses the size of particles became larger as the nucleation occurrence was lower than the total ions (Naghavi et al. 2010).

$$
\mathrm{H}_{2} \mathrm{O} \rightarrow \mathrm{e}_{\mathrm{aq}}{ }^{-}, \mathrm{H}_{3} \mathrm{O}^{+}, \mathrm{H}_{2}, \mathrm{H} \bullet, \mathrm{OH} \bullet, \mathrm{H}_{2} \mathrm{O}_{2}
$$

The present of CTAB surfactant plays an important role as the shape controlling agent and to prevent the aggregation activity of particles (Kaczmarek et al.

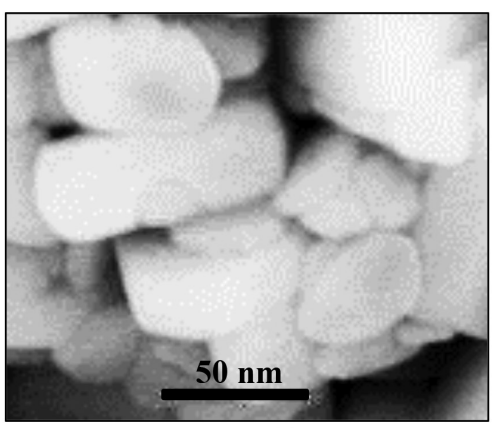

(a)

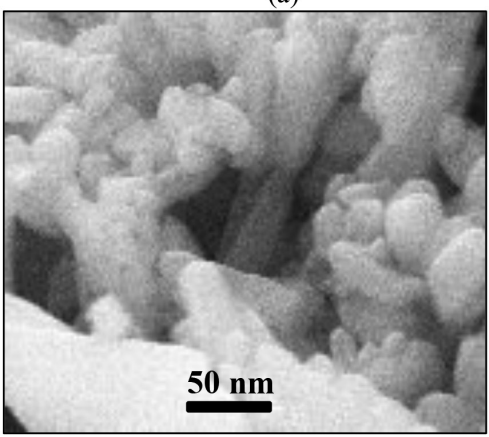

(c)
2015). At higher irradiation doses, the CTAB forming a well scattered of thin layer on top of the particles that produced smaller, well dispersed and grain-like formation of particles.

The emission spectra of $\mathrm{Gd}_{1.90} \mathrm{O}_{2} \mathrm{~S}: 10 \% \mathrm{Pr}^{3+}$ nanophosphors are illustrated in Figure 5. The photoluminescence study was carried out under $325 \mathrm{~nm}$ excitation of wavelength at room temperature. It can be seen that the highest and optimum emission intensity obtained was $50 \mathrm{kGy}$ sample. On the other hand, as the irradiation dose reached $100 \mathrm{kGy}$, the emission intensity started to decline. This happened as the samples irradiated with higher doses tend to decrease its particles size (based on Figure 4(c) and Figure 4(d)), as a result, the emission intensity will also decrease (He et al. 2015). The small size of particles will not increase the emission intensity of phosphors (Wang et al. 2013), but the major factor was smooth surface morphology of the particles (Sonika et al. 2015).

The emission spectra produced for all the samples demonstrated identical spectral outline, which confirmed that the outline attributed to the characteristics emission of $\mathrm{Pr}^{3+}$ ions. The most intense emission peaks were located at the green emission of $515 \mathrm{~nm}$ that corresponded to the ${ }^{3} \mathrm{P}_{0}-{ }^{3} \mathrm{H}_{4}$ transition of $\mathrm{Pr}^{3+}$ ions (Bagheri et al. 2016). Furthermore, the weak emission peaks can be observe positioned at 546 and $638 \mathrm{~nm}$. The emission peaks were matched to the ${ }^{3} \mathrm{P}_{1}-{ }^{3} \mathrm{H}_{5}$ and ${ }^{3} \mathrm{P}_{0}-{ }^{3} \mathrm{H}_{6}$ transitions of $\mathrm{Pr}^{3+}$ ions, respectively (Lian et al. 2015, 2011, 2010, 2009).

To extend our studies on photoluminescence properties of $\mathrm{Gd}_{2} \mathrm{O}_{2} \mathrm{~S}: \mathrm{Pr}^{3+}$, we chose the $50 \mathrm{kGy}$ as the most optimum

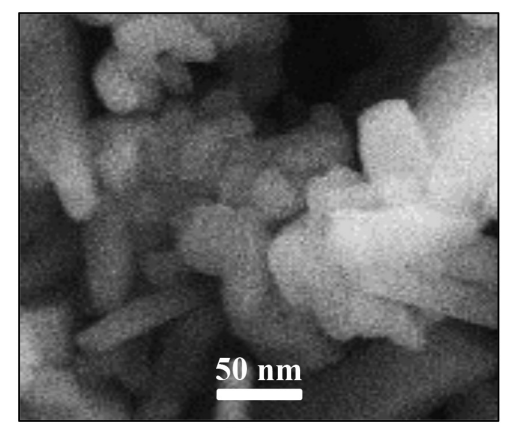

(b)

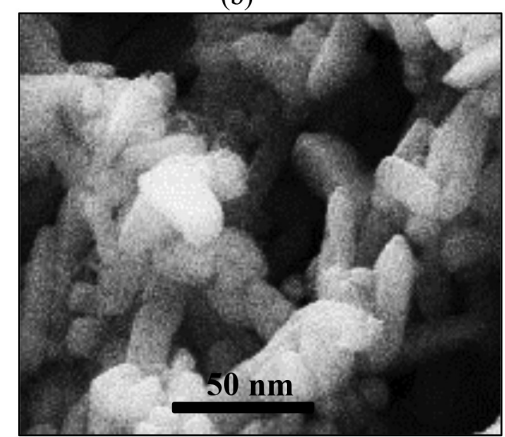

(d)

FIGURE 4. FESEM images of $\mathrm{Gd}_{1.90} \mathrm{O}_{2} \mathrm{~S}: 10 \% \mathrm{Pr}^{3+}$ nanophosphors: (a) $0 \mathrm{kGy}$, (b) $50 \mathrm{kGy}$, (c) $100 \mathrm{kGy}$ and (d) $150 \mathrm{kGy}$ 


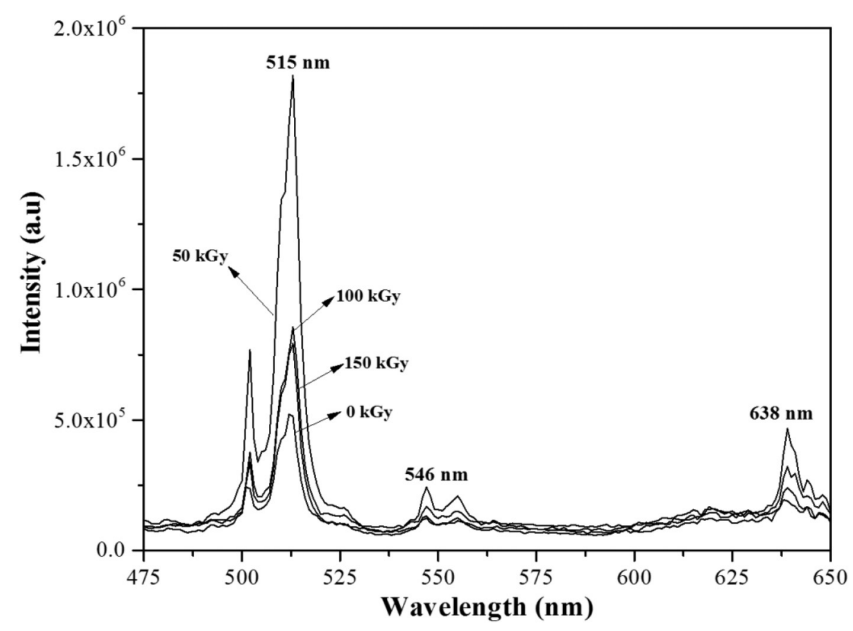

FIGURE 5. Emission spectra of the $\mathrm{Gd}_{1.90} \mathrm{O}_{2} \mathrm{~S}: 10 \% \mathrm{Pr}^{3+}$ nanophosphors irradiated at $0,50,100$ and $150 \mathrm{kGy}$

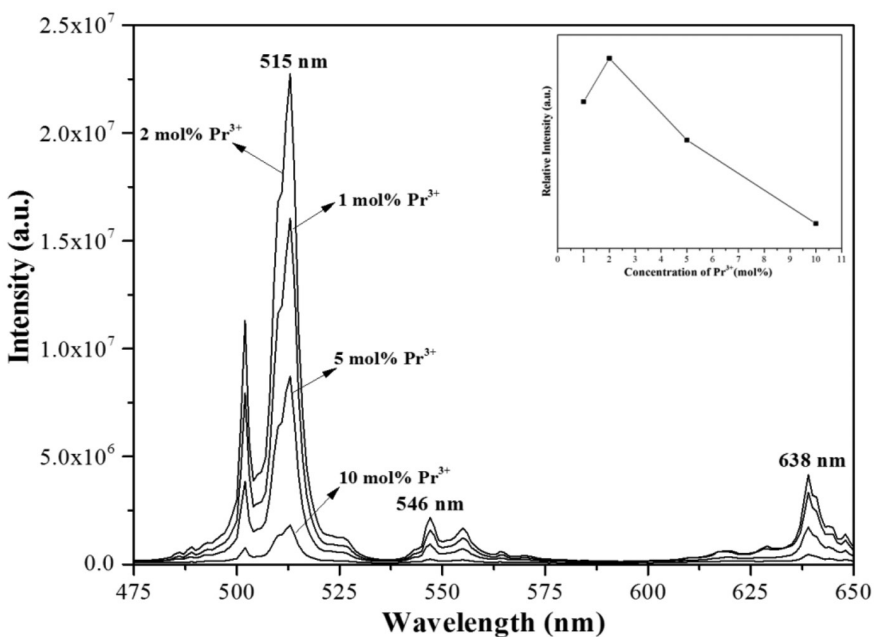

FIGURE 6. Emission spectra of the $\mathrm{Gd}_{2-x} \mathrm{O}_{2} \mathrm{~S}: x \mathrm{Pr}^{3+}(x=1,2,5$ and $10 \mathrm{~mol} \%)$ nanophosphors irradiated with $50 \mathrm{kGy}$ (The inset shows relative intensity of different mol\% of $\mathrm{Pr}^{3+}$ )

irradiation dose and synthesized the nanophosphors by difference concentration dopant of $\mathrm{Pr}^{3+}$ ions. The concentration of the dopant were 1, 2, 5 and $10 \mathrm{~mol} \%$. Based on Figure 6 and inset figure, the emission intensity reached the highest when the concentration of $\mathrm{Pr}^{3+}$ ion used was $2 \mathrm{~mol} \%$. As the concentration further increased, the emission intensity started to decline and it was believed due to the concentration quenching effect (He et al. 2015). The effect was caused by the shifting mutual non-radiative which faded the luminous intensity, the phenomenon occurs as the space between two adjacent of $\operatorname{Pr}^{3+}$ ions became closer when the interaction turns out to be much stronger (He et al. 2015).

\section{CONCLUSION}

A novel gamma irradiation method was successfully used to synthesize $\mathrm{Gd}_{2} \mathrm{O}_{2} \mathrm{~S}: \mathrm{Pr}^{3+}$ nanophosphors. Based on the
XRD patterns, single pure hexagonal phase was obtained. Furthermore, the crystallinity of the samples increased as the irradiation doses increases. The FESEM images showed the non-symmetrical shape and large size turns to smaller size and grain-like shape of particles. The optimal emission intensity of $\mathrm{Gd}_{2} \mathrm{O}_{2} \mathrm{~S}: \mathrm{Pr}^{3+}$ obtained was at $50 \mathrm{kGy}$ irradiation dose combined $2 \mathrm{~mol} \%$ concentration dopant of $\mathrm{Pr}^{3+}$ ion. In summary, the use of gamma irradiation method efficiently enhanced the properties of $\mathrm{Gd}_{2} \mathrm{O}_{2} \mathrm{~S}: \mathrm{Pr}^{3+}$ to fabricate for various applications. Lastly, we are hoping that the gamma irradiation method will draw more interest in various fundamental studies and synthesis of any materials in the future.

\section{ACKNOWLEDGEMENTS}

The authors would like to acknowledge the research grants from UKM (GUP-2018-060, GUP-2016-010) and UKM (AP- 
2015-006) for the financial supports. The authors are also thankful for the characterization support from the Centre for Research and Instrumentation Management (CRIM), UKM.

\section{REFERENCES}

Bagheri, A., Saraee, K.R.E., Shakur, H.R. \& Zeinali, H.Z. 2016. Synthesis and characterization of physical properties of $\mathrm{Gd}_{2} \mathrm{O}_{2} \mathrm{~S}: \mathrm{Pr}^{3+}$ semi-nanoflower phosphor. Applied Physics A 122(5): 553.

Dwivedi, Y. \& Zilio, S. 2013. Infrared cascade and cooperative multicolor upconversion emissions in $\mathrm{Y}_{8} \mathrm{~V}_{2} \mathrm{O}_{17}: \mathrm{Eu}: \mathrm{Yb}$ nanophosphors. Optics Express 21(4): 2555-2560.

Faruqi,A.R. \& Tyrell, G.C. 1999. Evaluation of gadolinium oxysulphide (P43) phosphor used in CCD detectors for electron microscopy. Ultramicroscopy 76(1-2): 69-75.

Greskovich, C. \& Duclos, S. 1997. Ceramic scintillators. Annual Review of Materials Science 27(1): 69-88.

Hasim, M.H., Rahman, I.A., Rahim, S., Ayob, M.T.M., Sharin, S. \& Radiman, S. 2017. Study on the effect of $\gamma$-irradiation on gadolinium oxysulfide nanophosphors $\left(\mathrm{Gd}_{2} \mathrm{O}_{2} \mathrm{~S}-\mathrm{NPs}\right)$. Journal of Nanomaterials 2017: Article ID. 7431432.

He, C., Xia, Z. \& Liu, Q. 2015. Microwave solid state synthesis and luminescence properties of green-emitting $\mathrm{Gd}_{2} \mathrm{O}_{2} \mathrm{~S}: \mathrm{Tb}^{3+}$ phosphor. Optical Materials 42: 11-16.

Huang, J., Song, Y., Sheng, Y., Zheng, K., Li, H., Zhang, H., Huo, Q., Xu, X. \& Zou, H. 2012. $\mathrm{Gd}_{2} \mathrm{O}_{2} \mathrm{~S}: \mathrm{Eu}^{3+}$ and $\mathrm{Gd}_{2} \mathrm{O}_{2} \mathrm{~S}: \mathrm{Eu}^{3+} /$ $\mathrm{Gd}_{2} \mathrm{O}_{2} \mathrm{~S}$ hollow microspheres: Solvothermal preparation and luminescence properties. Journal of Alloys and Compounds 532: 34-40.

Jurkin, T., Gotić, M., Štefanić, G. \& Pucić, I. 2016. Gammairradiation synthesis of iron oxide nanoparticles in the presence of PEO, PVP or CTAB. Radiation Physics and Chemistry 124: 75-83.

Kaczmarek, A.M., Hecke, K.V. \& Deun, R.V. 2015. Nano- and micro-sized rare-earth carbonates and their use as precursors and sacrificial templates for the synthesis of new innovative materials. Chemical Society Reviews 44(8): 2032-2059.

Lian, J., Qin, H., Liang, P., Wang, B. \& Liu, F. 2015. Controllable synthesis and photoluminescence properties of $\mathrm{Gd}_{2} \mathrm{O}_{2} \mathrm{~S}: x \% \mathrm{Pr}^{3+}$ microspheres using an urea-ammonium sulfate (UAS) system. Ceramics International 41(2): 29902998.

Lian,J., Sun, X., Li, J.G. \& Li, X. 2011. Synthesis, characterization and photoluminescence properties of $\left(\mathrm{Gd}_{0.99}, \mathrm{Pr}_{0.01}\right)_{2} \mathrm{O}_{2} \mathrm{~S}$ submicrophosphors by homogeneous precipitation method. Optical Materials 33: 596-600.

Lian, J., Sun, X., Li, J.G., Xiao, B. \& Duan, K. 2010. Characterization and optical properties of $\left(\mathrm{Gd}_{1-x}, \mathrm{Pr}_{x}\right)_{2} \mathrm{O}_{2} \mathrm{~S}$ nano-phosphors synthesized using a novel co-precipitation method. Materials Chemistry and Physics 122(2-3): 354-361.

Lian, J., Sun, X., Gao, T., Li, Q.,Li, X.\& Liu, Z. 2009. Preparation of $\mathrm{Gd}_{2} \mathrm{O}_{2} \mathrm{~S}$ : $\mathrm{Pr}$ scintillation ceramics by pressureless reaction sintering method. Journal of Materials of Science \& Technology 25(2): 254-258.

Liu, Z., Sun, X., Xu, S., Lian, J., Li, X., Xiu, Z., Li, Q., Huo, D. \& Li, J.G. 2008. $\mathrm{Tb}^{3+}$-and $\mathrm{Eu}^{3+-}$ doped lanthanum oxysulfide nanocrystals. Gelatin-templated synthesis and luminescence properties. Journal of Physical Chemistry C 112(7): 23532358.

Manam, J., Chatterjee, V., Das, S., Choubey, A. \& Sharma, S.K. 2010. Preparation, characterization and study of optical properties of $\mathrm{ZnS}$ nanophosphor. Journal of Luminescence 130(2): 292-297.

Manigandan, R., Giribabu, K., Suresh, R., Munusamy, S., Praveen Kumar, S., Muthamizh, S., Dhanasekaran, T., Padmanaban, A. \& Narayanan, V. 2015. Synthesis, growth and photoluminescence behaviour of $\mathrm{Gd}_{2} \mathrm{O}_{2} \mathrm{SO}_{4}: \mathrm{Eu}^{3+}$ nanophosphors: The effect of temperature on the structural, morphological and optical properties. RSC Advances 5(10): 7515-7521.

Naghavi, K., Saion, E., Rezaee, K. \& Yunus, W.M.M. 2010. Influence of dose on particle size of colloidal silver nanoparticles synthesized by gamma radiation. Radiation Physics and Chemistry 79(12): 1203-1208.

Osseni, S.A., Lechevallier, S., Verelst, M., Perriat, P., DexpertGhys, J., Neumeyer, D., Garcia, R., Mayer, F., Djanashvili, K., Peters, J.A., Magdeleine, E., Gros-Dagnac, H., Celsis, P. \& Mauricot, R. 2014. Gadolinium oxysulfide nanoparticles as multimodal imaging agents for $\mathrm{T}_{2}$-weighted MR, X-ray tomography and photoluminescence. Nanoscale 6(1): 555564 .

Seferis, I., Michail, C., Valais, I., Zeler, J., Liaparinos, P., Fountos, G., Kalyvas, N., David, S., Stromatia, F., Zycha, E., Kandarakis, I. \& Panayiotakis, G. 2014. Light emission efficiency and imaging performance of $\mathrm{Lu}_{2} \mathrm{O}_{3}: \mathrm{Eu}$ nanophosphor under $\mathrm{X}$-ray radiography conditions: Comparison with $\mathrm{Gd}_{2} \mathrm{O}_{2} \mathrm{~S}$ :Eu. Journal of Luminescence 151: 229-234.

Sharin, S., Rahman, I.A., Ahmad, A.F., Mohd, H.M.K., Mohamed, F., Radiman, S., Yasir, M.S., Sukiman, S., Ayob, M.T.M.\& Ahmad, B.I.S. 2015. Reduction of graphene oxide to graphene by using gamma irradiation. Malaysian Journal of Analytical Sciences 19(6) 1223-1228.

Som, S., Choubey,A.\& Sharma, S.K. 2013. Spectral and trapping parameters of $\mathrm{Eu}^{3+}$ in $\mathrm{Gd}_{2} \mathrm{O}_{2} \mathrm{~S}$ nanophosphor. Journal of Experimental Nanoscience 10(5): 1-21.

Sonika, Khatkar, S.P., Khatkar, A., Kumar, R. \& Taxak, V.B. 2015. Characterization and luminescence properties of colortunable $\mathrm{Dy}^{3+}$-doped $\mathrm{BaY}_{2} \mathrm{ZnO}_{5}$ nanophosphors. Journal of Electronic Materials 44(1): 542-548.

Wang, F., Liu, D., Yang, B. \& Dai, Y. 2013. Characteristics and synthesis mechanism of $\mathrm{Gd}_{2} \mathrm{O}_{2}: \mathrm{Tb}$ phosphors prepared by vacuum firing method. Vacuum 87: 55-59.

Wang, F., Yang, B., Zhang, J., Dai, Y. \& Ma, W. 2010. Highly enhanced luminescence of $\mathrm{Tb}^{3+}$-activated gadolinium oxysulfide phosphor by doping with $\mathrm{Zn}^{2+}$ ions. Journal of Luminescence 130(3): 473-477.

Wei, F., Xiyan, Z., Lixin, C. \& Liping, L. 2015. Preparation of $\mathrm{Gd}_{2} \mathrm{O}_{2} \mathrm{~S}: \mathrm{Er}^{3+}, \mathrm{Yb}^{3+}$ phosphor and its multiwavelength sensitive upconversion luminescence mechanism. CrystEngComm 17: $1881-1889$

Nuclear Technology Research Centre Faculty of Science and Technology

Universiti Kebangsaan Malaysia

43600 UKM Bangi, Selangor Darul Ehsan

Malaysia

*Corresponding author; email: irman@ukm.edu.my

Received: 24 April 2013

Accepted: 9 November 2017 